\title{
A place for aspiration in the treatment of spontaneous pneumothorax
}

\author{
J SPENCER JONES \\ From the Victoria Hospital, Deal, Kent
}

ABSTRACT In a retrospective survey of 195 patients with spontaneous pneumothorax, 100 had a deep $(>20 \%)$ air space. Thirty one patients were considered unsuitable for aspiration because of complicating disease. Sixty nine patients were treated by aspiration, and in 45 of these reexpansion was sufficient for the case to be managed as shallow pneumothorax while the patient remained ambulant. The average initial aspiration from the 69 patients was $1 \cdot 1$ litres. The intrapleural pressure was subatmospheric in only $22(49 \%)$ of the 45 successfully aspirated patients. A chest radiograph several hours after aspiration is the principal control required for this treatment. The recurrence rate was $11 \cdot 1 \%$. Of 95 patients with a shallow pneumothorax, 3 were intubated for progressive lung collapse and the remainder were encouraged to lead a normal life. The recurrence rate was $11.6 \%$. Retrospectively, it was concluded that 137 patients $(70 \%)$ had a closed pneumothorax at diagnosis. Primary intubation of all patients with a deep pneumothorax would have represented overtreatment.

Since 1981 several authors ${ }^{1-3}$ have redirected attention to the treatment of spontaneous pneumothorax by aspiration, using a narrow lumen catheter. The earlier method of treatment by needle aspiration has been falling into disuse despite still having its proponents, and Horne 4 treated it dismissively when he gave a definitive account of treatment by intubation. Crofton and Douglas ${ }^{5}$ do not mention aspiration by any method.

Since most patients with a non-disabling shallow pneumothorax $(<20 \%)$ are managed while remaining ambulant, it seemed very likely that some deep pneumothoraces might be aspirated until shallow and then managed as if they had been shallow from the start. This would avoid confining otherwise healthy individuals to hospital attached to a tube and bottle.

\section{Methods}

The records of 195 patients under my care consecutively diagnosed as having spontaneous pneumothorax were examined to see whether treatment by aspiration had been useful to some who might otherwise have been intubated. The data

Address for reprint requests: Dr J Spencer Jones, Victoria Hospital, Deal, Kent DT14 9UA.

Accepted 30 July 1984 were extracted from personally compiled records; although there was no formal follow up, the method of access to the records and arrangement of work make it unlikely that many relapses are not known.

The procedure for aspiration was the reverse of that previously used in the pneumothorax treatment of pulmonary tuberculosis. The patient was propped upright and a Morland pneumothorax trocar (a fine needle with side aperture) was inserted anteriorly through the second intercostal space of the affected side into the pleural cavity, without local anaesthesia. The intrapleural pressures were recorded with a Maxwell pneumothorax apparatus before and after aspiration of a volume of air, which averaged $1.1 \mathrm{l}$ over the series and which never exceeded 2.01 at the first attempt. After this, patients who felt comfortable waited quietly for about three hours for a further radiograph to show the effect of the aspiration. Some patients with a very deep pneumothorax then had a further aspiration to achieve a total of over 2.51 aspirated. Most patients were then sufficiently comfortable to make immediate arrangements to go home and to be managed as outpatients. The rule was that they should work if they wanted to.

\section{Results}

Of the 195 patients, $95(49 \%)$ with a shallow 
pneumothorax, were left untreated (one had the only bilateral pneumothorax in the series). Of these, three developed progressive collapse of the lung, which responded to intubation during the following week. In 15 there was a radiograph confirming a previous attack on the same side and 11 subsequently had radiographically proved relapses on the same side, giving a recurrence rate of $11.6 \%$.

Sixty nine patients (35\% of 195$)$ with a deep pneumothorax were treated by aspiration and 45 (65\% of those aspirated) thus obtained sufficient aeration of lung to be managed as having a shallow pneumothorax. These 45 patients consisted of 22 with subatmospheric, 15 with atmospheric, and eight with positive intrapleural pressures. Five patients had radiographs showing a previous pneumothorax on the same side and five others subsequently had a radiographically proved relapse on the same side, giving a recurrence rate of $11 \cdot 1 \%$. Of four aspirated patients whose lungs subsequently collapsed slowly, two obtained a stable, shallow pneumothorax after a further aspiration within one week and in two others the pneumothorax was absorbed during six weeks' outpatient observation. Thus in 137 cases, 92 without and 45 with aspiration $(70 \%)$, the pneumothorax was uninterruptedly absorbed.

Of the 24 patients whose aspiration was not followed by re-expansion of the lung, only four had a subatmospheric intrapleural pressure. Thirteen were treated successfully by intubation. Nine required thoracotomy, and one had a mesothelioma. For one bedridden emphysematous man the pneumothorax was a terminal event.

Thirty one patients were considered unsuitable for aspiration. They included three with a large haemopneumothorax, two with a chronic pneumothorax, and 26 with emphysema or pulmonary fibrosis or both. Eighteen in this group were treated by intubation, 13 successfully. Complications of intubation in this "difficult" group included one empyema thoracis and two deaths, one from respiratory failure and one from laceration of the lung by the introductory cannula.

\section{Discussion}

This study of 100 patients with a deep pneumothorax and 95 patients with a shallow pneumothorax left a clear impression that $45 \%$ of the deep pneumothoraces differed from shallow ones only in their size. Not only was the course after aspiration similar but the respective rates of known relapse were $11.1 \%$ and $11.6 \%$. Aspiration of air readily identified patients with deep pneumothorax who could be sent home instead of being confined to hospital for intubation. As Clague and El-Ansary ${ }^{6}$ observed, the intrapleural pressures did not reliably indicate the response to aspiration.

With hindsight, 137 patients $(70 \%)$ had a closed pneumothorax which could have been absorbed without intervention. This probably explains why the debate about the treatment of spontaneous pneumothorax has continued from the era of sanatorium treatment until the present day, and why $74 \%$ of Stradling and Poole's 119 patients responded to conservative management. ${ }^{7}$ No method of treatment is ever likely to appear in a really unfavourable light. Since most patients are going to recover, we should be sure to choose a primary treatment which is likely to return the patient to a normal life with the least inconvenience and delay. On these grounds aspiration, which need take no more than about three minutes, has to be considered inferior only to non-intervention as practised in cases of shallow pneumothorax. When aspiration has been decided on, the technique is a secondary consideration. It probably does not matter whether exsufflation is by a pneumothorax apparatus or by a syringe. The use of a needle is as simple as an intramuscular injection, but the use of a fine lumen catheter has the attraction of allowing aspiration of all but a small pocket of air from the pleural cavity.

The historical perspective shows that therapeutic pneumothorax was not favoured in older patients with tuberculosis but that the young were allowed to lead near normal lives with a lung partially collapsed. It therefore seems incongruous that intubation should often be chosen as a primary treatment for otherwise healthy young patients with a deep pneumothorax.

\section{References}

1 Raja OG, Lalor AJ. Simple aspiration of spontaneous pneumothorax. Br J Dis Chest 1981;75:207-8.

2 Bevelaqua FA, Aranda C. Management of spontaneous pneumothorax with small lumen catheter manual aspiration. Chest 1982;81:693-4.

3 Hamilton AAD, Archer GI. Treatment of spontaneous pneumothorax by simple aspiration. Thorax 1983; 38: 934-6.

4 Horne NW. Spontaneous pneumothorax: diagnosis and management. $\mathrm{Br}$ Med J 1966;i:281-4.

5 Crofton J, Douglas A. Respiratory diseases. Oxford: Blackwell Scientific Publications, 1981:545.

6 Clague HW, El-Ansary EH. Conservative management of spontaneous pneumothorax. Lancet 1984; i:688 (letter).

7 Stradling P, Poole G. Conservative management of spontaneous pneumothorax. Thorax 1966;21:145-9. 